\title{
Renal tubular cell regeneration, cell proliferation and chronic nephrotoxicity in the goldfish Carassius auratus following exposure to a single sublethal dose of hexachlorobutadiene
}

\author{
R. Reimschuessel, R. O. Bennett, E. B. May, M. M. Lipsky \\ Department of Pathology, 711 MSTF, University of Maryland School of Medicine, 10 S. Pine Street, Baltimore, Maryland 21201. \\ USA
}

\begin{abstract}
Regeneration of the epithelium following injury is a vital process in many organs of both mammals and fish. An understanding of this response is essential when evaluating the impact of xenobiotics on tissues such as the kidney. The present studies demonstrate regeneration of the goldfish Carassius auratus renal proximal tubular epithelium following toxicant induced injury (hexachlorobutadiene, $\mathrm{HCBD} 500 \mathrm{mg} \mathrm{kg}^{-1}$ ). $\mathrm{HCBD}$-induced vacuolation and necrosis of the proximal tubular epithelium were observed within $24 \mathrm{~h}$ and continued for $10 \mathrm{wk}$ following the single intraperitoneal injection. A flattened, basophilic regenerating epithelium was observed along the intact basement membrane $1 \mathrm{wk}$ post HCBD-treatment. In the following weeks, as the regenerating epithelial cells differentiated, they developed vacuoles and became necrotic. ln addition. 2 wk after exposure, newly formed nephrons developed from basophilic cell clusters adjacent to collecting ducts. Ten weeks following the single HCBD injection, fibrotic glomeruli and large dilated proximal segments with altered morphology were present. The rate of cell turnover in normal and injured kidneys was determined using bromodeoxyuridine (BrdU) pulse and repetitive labeling. BrdU labeling indices were elevated in the regenerating tubules, distal segments, collecting ducts, basophilic cell clusters and developing nephrons of HCBD-treated fish. Intense labeling occurred in the collecting ducts $4 \mathrm{~d}$ after HCBD-administration. BrdU incorporated into cells on Day 4 was noted in the regenerating epithelial cells on Day 7 , indicating that these cells are probably derived from cells in the lower portions of the nephron. Labeling indices remained elevated in proximal segments 10 wk following toxicant administration.
\end{abstract}

\section{INTRODUCTION}

The kidney's ability to repair sublethal toxic injury has been well documented in the mammal. Numerous nephrotoxins have been used to demonstrate the pattern of cellular repopulation along the second and third segments of the rat proximal tubule. Among these are mercuric chloride (Cuppage \& Tate 1967, Haagsma \& Pound 1980, Boti et al. 1982), uranium nitrate (Oliver 1915), gentamicin (Houghton et al. 1976, Wellwood et al. 1976) and hexachlorobutadiene (Ishmael et al. 1982). Hexachlorobutadiene (HCBD) is a useful toxicant for such studies because it is extremely nephrotoxic without causing hepatotoxicity.

HCBD is a chlorinated hydrocarbon widely distributed in the environment (Pearson \& McConnel 1975,
Laska et al. 1976, Yip 1976. Yurawecz et al. 1976, IARC 1979. USEPA 1980). Its acute renal toxicity has been demonstrated in both mammals (Gage 1970, Lock \& Ishmael 1979, Stott et al. 1981a) and fish (Reimschuessel et al. 1989). The renal proximal tubule epithelium in fish and mammals becomes vacuolated and necrotic. In the mammal, renal tubular regeneration begins approximately 3 to $4 \mathrm{~d}$ following injection of a sublethal dose of HCBD (Ishmael et al. 1982). The basic pattern of regeneration following exposure to $\mathrm{HCBD}$ and other nephrotoxins is similar. Repopulation of the proximal tubules is accomplished by cell migration and cellular division. A mature cuboidal epithelium develops from flattened basophilic cells which migrate along the intact basement membrane and divide.

Renal tubular regeneration following toxicity has not 

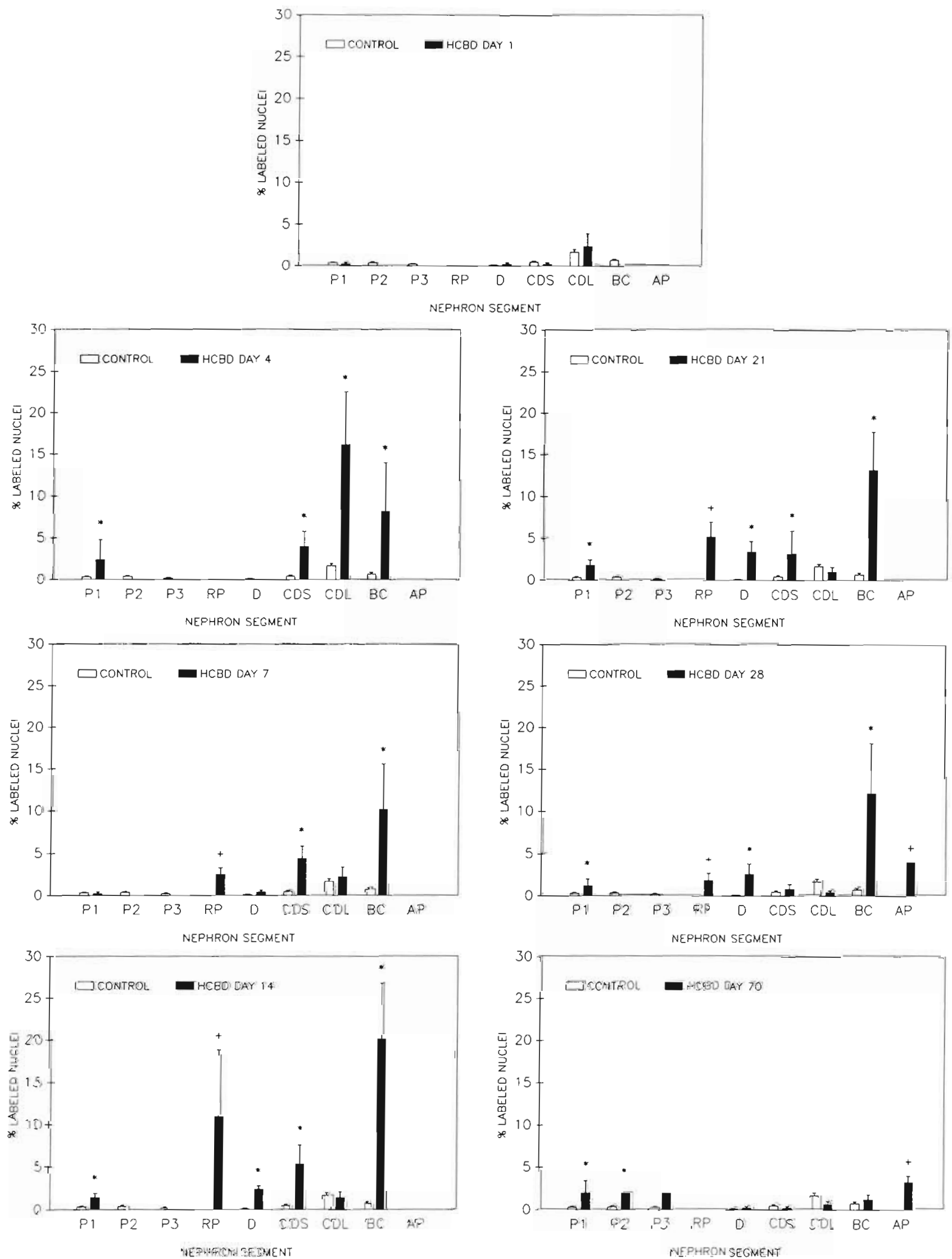
been described in fish. Since histopathological changes in fish tissues are increasingly being used to evaluate the impact of contaminants in the aquatic environment, it is essential to understand and recognize basic responses of fish tissues to injury (Sindermann et al. 1980, Johnson \& Bergman 1984, Hinton et al. 1987). Little is known about the morphology of the reparative process in fish kidneys. Still less is known about the rates of cell turnover in normal and injured renal cells. Changes in cell proliferation can be used to demonstrate the sensitivities of different aquatic organisms to toxic xenobiotics (Droy et al. 1988). Increases in cell proliferation may also lead to carcinogenesis or neoplastic progression (Stott et al. 1981b). Normal cell turnover rates in fish tissues must, however, be determined before we can evaluate the effects of toxicants on cellular proliferation.

The goals of the present study were to (1) evaluate the chronic nephropathology caused by a single HCBD-treatment; (2) to characterize the patterns of repair and epithelial regeneration in the goldfish Carassius auratus kidney; and (3) to determine the rate of cell turnover in normal and injured goldfish nephrons.

\section{MATERIALS AND METHODS}

General procedures. Ninety-five goldfish Carassius auratus between 10 and $15 \mathrm{~cm}$ long were obtained from a local distributor. The fish were maintained and treated as previously described (Reimschuessel et al. 1989]. Briefly, HCBD-treated fish were given a single intraperitoneal (ip) injection of $500 \mathrm{mg} \mathrm{kg}^{-1} \mathrm{HCBD}$ dissolved in corn oil. Control fish received an ip injection of an equal volume $\left(10 \mathrm{ml} \mathrm{kg} \mathrm{kg}^{-1}\right)$ of corn oil. The thymidine analogue, 5-bromo, 2'deoxyuridine (BrdU), was administered in 3 different protocols:

Experiment 1. BrdU pulse label $4 \mathrm{~h}$ before sacrifice. Seventy fish (in groups of 5 HCBD-treated and 5 control fish) were sacrificed after $1,4,7,14,21,28$ and $70 \mathrm{~d}$ exposure. These fish received an ip injection of $500 \mathrm{mg}$ $\mathrm{kg}^{-1}$ BrdU $4 \mathrm{~h}$ before sacrifice. This protocol was used to determine which cells were synthesizing DNA at various times following the injury.
Experiment 2. BrdU label on Day 4, 3 d prior to sacrifice. Ten fish (5 HCBD-treated and 5 control fish) received 3 ip injections of $100 \mathrm{mg} \mathrm{kg}^{-1}$ BrdU 4 h apart on Day 4 after HCBD-treatment and were sacrificed on Day 7. An additional $5 \mathrm{HCBD}$-treated fish received the same dose and number of BrdU injections on Day 7 and were sacrificed $4 \mathrm{~h}$ after the last BrdU injection. This protocol establishes which cells are responsible for repopulating the nephron by demonstrating the fate of cells synthesizing DNA shortly after HCBD-induced injury.

Experiment 3. BrdU 'continuous' label Days 4 through 7. Ten fish (5 HCBD-treated and 5 control fish) received 3 ip injections of $100 \mathrm{mg} \mathrm{kg}^{-1} \mathrm{BrdU} 4 \mathrm{~h}$ apart on Day 4 and then single $100 \mathrm{mg} \mathrm{kg}^{-1}$ BrdU injections on Days 5, 6, and 7. Fish were sacrificed 4 h after BrdU injection on Day 7. This protocol detects which cells had synthesized DNA and divided between Day 4 and 7 . when the regenerating epithelium appears. 'Continuous' labeling detects cycling cells that are missed when short pulses of BrdU are given.

Tissue preparation. Following sacrifice, the caudal kidneys were removed, sliced and immediately immersed in $4 \%$ formaldehyde and $1 \%$ glutaraldehyde fixative (4F1G) (McDowell \& Trump 1976) for routine embedding in paraffin. Sections ( $6 \mu \mathrm{m})$ were stained with hematoxylin and eosin. BrdU incorporation into cell nuclei was demonstrated using immunohistochemical techniques (Reimschuessel et al. in press). Gamma glutamyl transpeptidase (GGT) enzyme histochemistry was used to detect proximal segments 2 and 3 (Reimschuessel et al. 1989). Sections were counter stained with Weigert's acid iron chloride hemalum counterstain (Vacca 1985). GGT staining was performed on one control and one treated fish at each time period. Von Kossa stain for calcium was done on selected sections (Luna 1968).

Nephron segmentation and nomenclature. The goldfish Carassius auratus nephron consists of a glomerulus (G), 3 proximal segments (P1, P2, P3) and a distal tubule (D). There is some disagreement about the segmentation of the goldfish nephron (Edwards \& Schnitter 1933, Longley \& Fisher 1954, Ogawa 1962, Hickman \& Trump 1969, Endo \& Kimura 1982, Sakai 1985, Hentschel \& Elger 1988). According to both

Fig. 1. Carassius auratus. Percent labeled nuclei in different nephron segments of control and HCBD-treated fish given BrdU 4 h prior to sacrifice. On Day 1 following HCBD-injection labeling indices were the same as those of control fish. HCBD-treated fish: On Day 4, there was a significant increase in labeling in the epithelium of the small and large collecting ducts, P1 and the basophilic clusters. By Week 1, labeling was present in the regenerating epithelial cells. The epithelium of large collecting ducts no longer exhibited increased labeling. Small collecting ducts and basophilic clusters continued to incorporate BrdU. During the following weeks P1, the regenerating epithelium, distal segments and small collecting ducts showed an elevated labeling index. Even by Week 10, the labeling index in the proximal segments remained significantly higher than that of the control fish Abbreviations are: (P1, P2, P3) proximal segments 1,2,3; (RP) regenerating proximal segments; (D) distal segments; (CDS) small collecting ducts: (CDL) large collecting ducts; (BC) basophilic clusters; (AP) 'altered proximal segments. $p<0.05$ for $\left({ }^{\circ}\right)$ treated vs control or (+) RP/AP vs proximal segment of control 

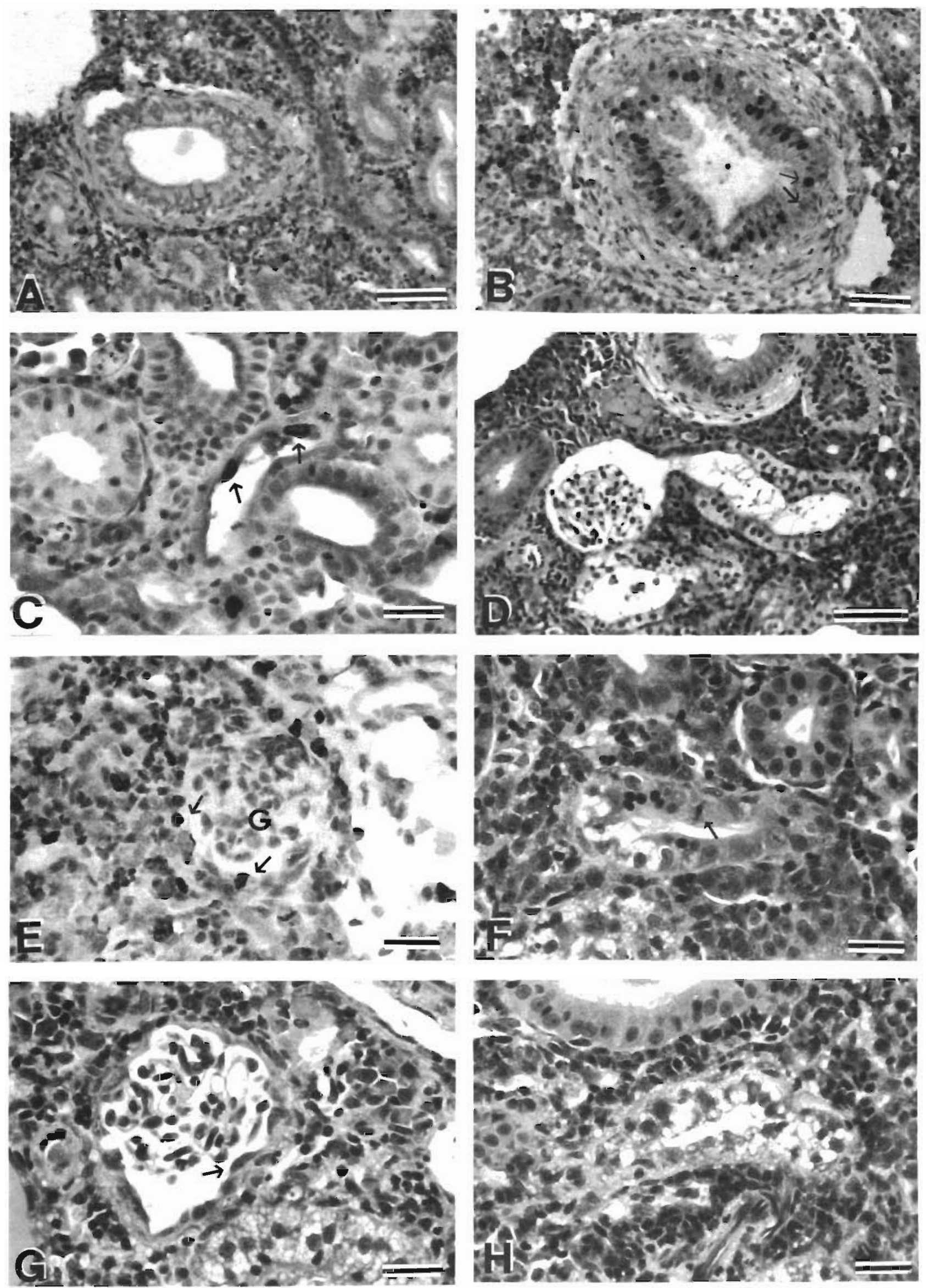
Edwards \& Schnitter (1933) and Longley \& Fisher (1954) there is a short, ciliated neck segment, 2 proximal segments, a ciliated intermediate segment, a distal segment and collecting ducts. Endo \& Kimura (1982) and Ogawa (1962), claim the intermediate segment is rarely in the goldfish. Sakai (1985) describes a nephron with no neck segment, 3 proximal segments, but no intermediate segment. The third proximal segment Sakai describes is ciliated. Hickman \& Trump (1969) suggest that the intermediate segment may be regarded as a specialization of the terminal end of the second proximal segment. Hentschel \& Elger (1988) also describe this section of the nephron as a proximal tubule. Because this segment has both morphological characteristics distinct from the second proximal segment (P2), and features of proximal segments, it will be referred to here as the third proximal segment (P3). The distal tubules join small collecting ducts (CDS) which combine with larger collecting ducts (CDL).

Statistics and cell counts. Random fields of sections were examined microscopically and the different tubular segments identified. One hundred epithelial cell nuclei were counted in each segment and the percent labeling determined. There was no significant difference in the percent labeled nuclei in the different segments of the control kidneys at the different time periods in Expt 1. Therefore, the control results at the different time periods of Expt 1 were pooled.

Analysis of variance (ANOVA) and Student's t-tests were performed on an IBM PC using the SAS for the PC software package (SAS Institute Inc, SAS Circle, Box 8000, Cary, NC 27512-8000).

\section{RESULTS}

Control fish did not show any gross or behavioral changes. The HCBD-treated fish on Days 1 and 4 developed ascites and exophthalmia which resolved during the first week (Reimschuessel et al. 1989). By Day 7, HCBD-treated fish had resumed normal swim- ming patterns, ate eagerly and exhibited no external signs. The fish continued to look and behave normally through to Day 70 .

\section{Experiment 1: BrdU pulse label $4 \mathrm{~h}$ before sacrifice}

The labeling indices at the different time periods are summarized in Fig. 1.

\section{Control fish}

Control fish had normal-appearing nephrons. The goldfish Carassius auratus nephron consists of a glomerulus $(G), 3$ proximal segments (P1, P2, P3) and a distal tubule (D). The distal tubules join small collecting ducts (CDS) which combine with larger collecting ducts (CDL). There are also occasional clusters of basophilic cells adjacent to the collecting ducts. Newly developed nephrons, arising from the basophilic cell clusters (BC), are rarely seen in the normal goldfish kidney. The second and third proximal tubules of the control fish demonstrated intense Gamma glutamyl transpeptidase (GGT) activity at all times (Reimschuessel et al. 1989). Minimal BrdU labeling was noted in the nephrons of control fish. The mean percent labeled nuclei for the proximal and distal segments along the nephron was less than $0.4 \%$. The collecting ducts exhibited less than $2 \%$ labeling and the basophilic clusters less than $1 \%$ nuclear labeling (Fig. 2A).

HCBD-treated fish

Week 1

The histopathologic changes noted on Days 1, 4 and 7 have been described (Reimschuessel et al. 1989). Briefly, the epithelial cells of the proximal tubules became vacuolated and necrotic. On Days 1 and 4 there was no apparent epithelial regeneration in the

Fig. 2. Carassius auratus. (A) Immunoperoxidase staining of BrdU incorporation in a large collecting duct of a control fish on Day 4. Few epithelial cell nuclei are labeled. Hematoxylin counterstain; bar $=50 \mu \mathrm{m}$. (B) Immunoperoxidase staining of BrdU incorporation in a large collecting duct on Day 4 after HCBD-treatment. Numerous epithelial cell nuclei are labeled. Thick arrow: unlabeled nucleus; thin arrow BrdU labeled nucleus; hematoxylin counterstain; bar $=50 \mu \mathrm{m}$. (C) Immunoperoxidase staining of BrdU incorporation in regenerating proximal epithelium on Day 7 after HCBD-treatment. Two nuclei of the flattened epithelium in this section contain BrdU (arrows). Hematoxylin counterstain, bar $=20 \mu \mathrm{m}$. (D) Dilated renal corpusle and vacuolated P1 segment $2 \mathrm{wk}$ following $\mathrm{HCBD}$-administration. Hematoxylin and eosin stain; bar $=50 \mu \mathrm{m}$. (E) Immunoperoxidase staining (arrows) of BrdU incorporation in nuclei of the parietal epithelium of a glomerulus (G) 2 wk following HCBD-administration. Hematoxylin counterstain; bar $=20 \mu \mathrm{m}$. (F) Regenerating proximal epithelium $2 \mathrm{wk}$ following HCBD-administration. The epithelium has developed more mature characteristics and several cells are vacuolated. Note the mitotic figure (arrow). Hematoxylin and eosin stain; bar $=20 \mu \mathrm{m}$. (G) Glomerulus with thickened parietal epithelium (arrow) and Bowman's capsule 3 wk following HCBD-treatment. Hematoxylin and eosin stain; bar $=20 \mu \mathrm{m}$. $(\mathrm{H})$ Vacuolated regenerating proximal epithelium 3 wk following HCBD-administration. The collecting duct at the top has a normal appearing epithelium. Hematoxylin and eosin stain; bar $=20 \mu \mathrm{m}$ 

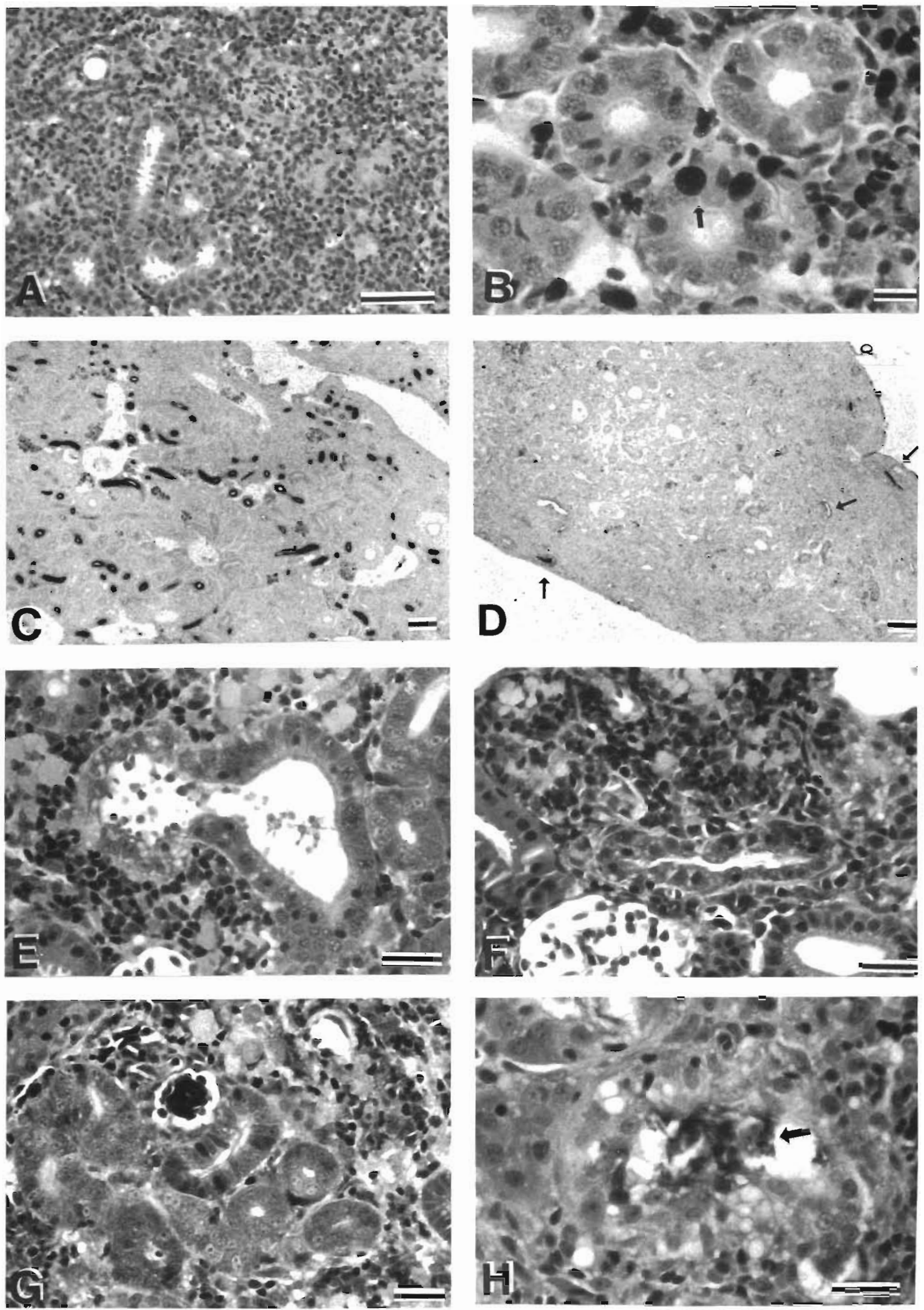
treated fish. On Day 1, there was no significant increase in the BrdU staining in the tubule cell nuclei, collecting ducts or basophilic clusters in the treated fish. Four days after HCBD injection, numerous nuclei were labeled in the large collecting ducts (16\%) (Fig. 2B), smaller collecting ducts (4\%) and basophilic clusters $(8 \%)$. These values were significantly greater $(\mathrm{p}<0.001)$ than those of the controls (Fig. 1).

By Day 7 , dilated renal corpusles and dilated tubules contained regenerating, flattened, basophilic epithelial cells along the intact basement membrane. Some of the regenerating epithelial cells contained BrdU label (3\%) (Fig. 2C) and an occasional mitotic figure was observed. BrdU labeling was also observed in the basophilic clusters $(10 \%, p<0.001)$ and smaller collecting ducts $(4 \%, p<0.001)$.

\section{Week 2}

Two weeks following HCBD injection, when the fish were normal in appearance and eating well, kidneys still demonstrated striking morphologic alterations. There appeared to be fewer tubules in the basophilic interstitium. Some glomeruli had a cleared-out appearance, with a dilated Bowman's space (Fig. 2D). Other glomeruli had a somewhat thickened and basophilic parietal epithelium. The nuclei of these cells sometimes contained BrdU label (Fig. 2E)

The epithelial cells in P1 contained many small, clear vacuoles with occasional bright eosinophilic cytoplasmic blebs extending into the lumen of the tubule. The nuclei were small and displaced from their normally basal location into the center of the cell (Fig. 2D). Some P1 epithelial cells were necrotic and fragmented and the tubule lumen contained eosinophilic debris and pyknotic nuclei.

Normal P2 and P3 segments were not observed Some narrow regenerating proximal tubules staining a lavender color had eosinophilic cilia in their lumens resembling normal P3 tubules. The regenerating epithelium was, however, very pleomorphic. The cells were flattened in some areas and piled up on each other in other sections of the tubule. Some of these epithelial cells contained small vacuoles or were necrotic (Fig. 2F). Necrotic debris was present in the lumens of some regenerating tubules. Weak GGT staining was observed in some vacuolated tubules.

The epithelial cells of the distal tubules had normal morphology. Some distal tubules contained a dark, basophilic granular material that was positive for calcium when stained by the Von Kossa method.

The regenerating epithelium $(11 \%)$, distal tubules $(2 \%)$, smaller collecting ducts $(5 \%)$ and basophilic clusters $(20 \%)$ exhibited BrdU labeling significantly greater $(p<0.001)$ than that of the respective control segments.

\section{Week 3}

Three weeks after HCBD-exposure, P1 segments containing vacuolated epithelial cells could still be identified. Some of these tubules were widely dilated with cells compressed against the basement membrane. Some epithelial cells had a grainy eosinophilic appearance and others were necrotic with pyknotic nuclei. Rarely, some flattened basophilic cells were found along the basement membrane, interspersed between groups of vacuolated cells. Glomeruli were sometimes dilated while other glomeruli had a thickened Bowman's capsule (Fig. 2G).

Regenerating lavender epithelial cells had irregular shapes, very large nuclei and contained cytoplasmic vacuoles (Fig. 2H). Some regenerating tubules were dilated while others were narrow and had prominent eosinophilic cilia extending into the lumens.

Collecting ducts and distal tubules were prominent in a rather empty appearing basophilic interstitium (Fig. 3A). In some sections the distal tubules were distended and their epithelium was flattened by large calcium deposits. Occasional distal epithelial cells in these areas were necrotic. Numerous newly formed developing nephrons were noted adjacent to collecting ducts.

BrdU labeling was observed primarily in the regenerating proximal tubules $(5 \%)$, distal tubules $(3 \%)$ (Fig. 3B) and the basophilic clusters (13\%), all significantly greater $(p<0.001)$ than the respective

Fig. 3. Carassius auratus. (A) Kidney of goldfish 3 wk after HCBD-administration, showing small collecting ducts with few surrounding tubules. Hematoxylin and eosin stain; bar $=50 \mu \mathrm{m}$. (B) Immunoperoxidase staining of BrdU incorporation in the nuclei of distal tubules $3 \mathrm{wk}$ after HCBD-treatment (arrow). Hematoxylin counterstain; bar $=10 \mu \mathrm{m}$. (C) Gamma glutamyl transpeptidase staining of control fish kidney at 3 wk. Proximal segments 2 and 3 show intense reaction product in their lumens bar $=100 \mu \mathrm{m}$. (D) Gamma glutamyl transpeptidase staining 3 wk after HCBD-treatment. Only a few tubules contain a reaction product (arrows); bar $=100 \mu \mathrm{m}$. (E) 'Altered' proximal segment connected to vacuolated regenerating segment $4 \mathrm{wk}$ after HCBDadministration. Note the numerous cytoplasmic blebs extending into the lumens of both segments. Hematoxylin and eosin stain; bar $=20 \mu \mathrm{m} .(\mathrm{F})$ Regenerating proximal epithelium containing small cytoplasmic vacuoles $4 \mathrm{wk}$ after HCBD-administration Hematoxylin and eosin stain; bar $=20 \mu \mathrm{m}$. (G) Developing nephron 4 wk after HCBD-administration. Hematoxylin and eosin stain; bar $=20 \mu \mathrm{m}$. $(\mathrm{H})$ Mineral deposit in a regenerating segment $10 \mathrm{wk}$ following HCBD-treatment. This material was positive for calcium when stained with Von Kossa's stain. Hematoxylin and eosin stain; bar $=20 \mu \mathrm{m}$ 

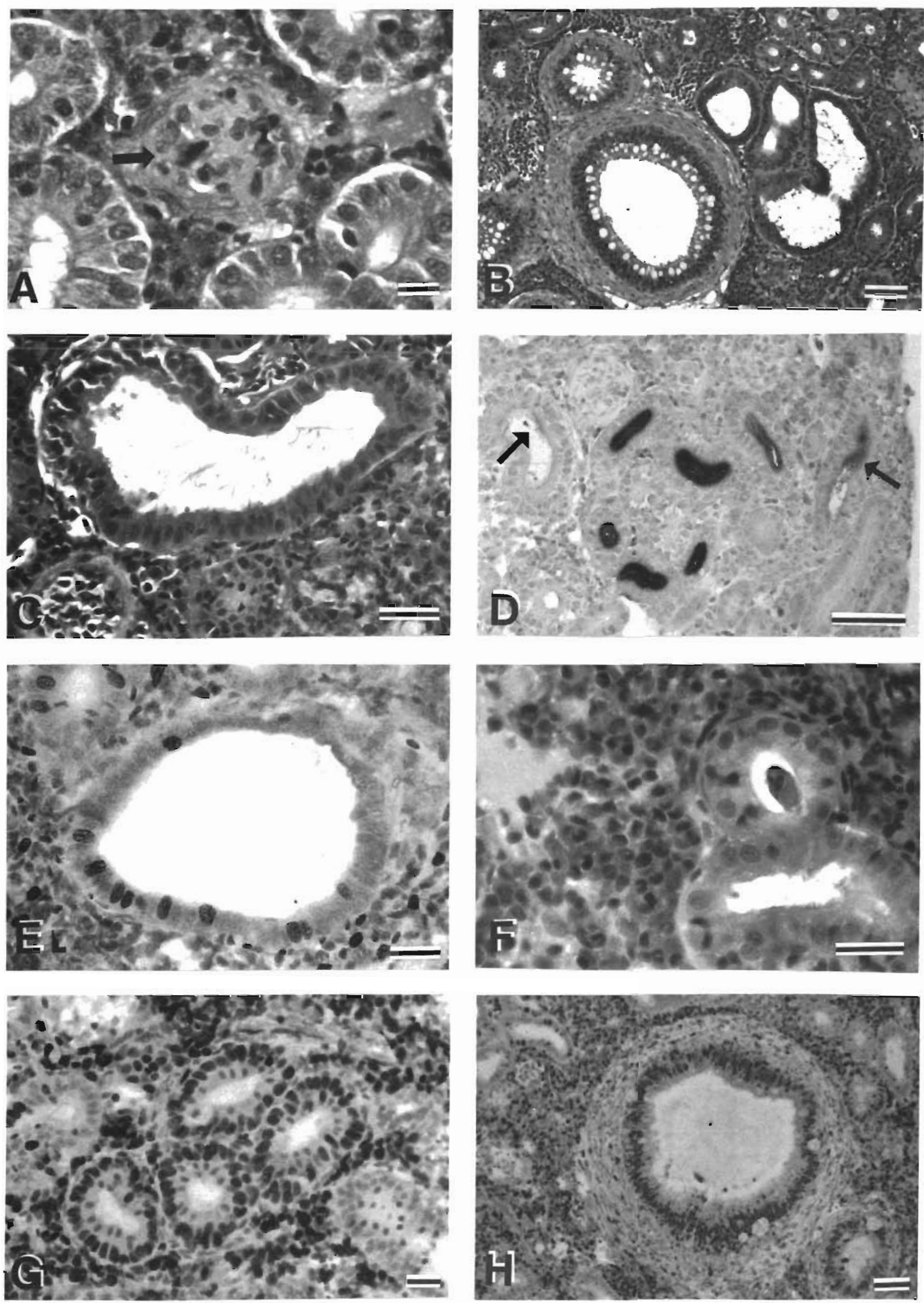
control values. Little to no GGT staining was observed at this time (Fig. 3C, D).

\section{Week 4}

Four weeks following exposure, some vacuolated, dilated P1 tubular segments were still evident in HCBD-treated fish. Present also were a few dilated, large tubules with very tall, columnar epithelial cells. These cells were dark and moderately basophilic. Their large, oval nuclei were located near the basement membrane. A brush border was present, along with occasional cilia and cytoplasmic blebs which protruded into the lumen from some of these epithelial cells. In a few areas the epithelium had a squamous appearance. In these areas the cells were irregularly stacked approximately 2 to 4 layers thick. The cell borders were indistinct, and sometimes the cytoplasm contained small vacuoles. Some of these tubules were connected to glomeruli, while others formed narrow connections with the lavender regenerating proximal tubules (Fig. 3E). No GGT staining was present in the large tubules with the tall columnar epithelium. Because of their location, these tubules will be referred to as 'altered' proximal segments (AP). Occasional nuclei in these segments were labeled with $\operatorname{BrdU}(4 \%)$.

Most of the lavender regenerating tubules were vacuolated, and some had cytoplasmic blebs bulging into the lumen (Fig. 3F). Many had collapsed in the interstitium and contained necrotic cells. This made them difficult to recognize and gave the interstitium a basophilic appearance. Only a few, narrow tubules had GGT activity. BrdU labeling was seen in some of the regenerating tubules ( $2 \%)$.

Glomeruli, distal tubules and collecting ducts were similar to those seen at Week 3. Developing nephrons were still present. Most of these nephrons were larger and less basophilic than those noted $3 \mathrm{wk}$ after HCBD exposure (Fig. 3G). BrdU labeling was seen in the distal tubules $(3 \%)$ and basophilic clusters $(12 \%)$ both significantly greater than the control values $(p<0.001)$.
Week 10

Ten weeks after the single HCBD injection, regenerating lavender tubules were rarely seen. Those that were present still had small vacuoles, and sometimes calcium deposits in their lumens (Fig. $3 \mathrm{H}$ ). There were end-stage fibrotic glomeruli in many of the sections (Fig. 4A). Some of the kidneys had foci that were devoid of tubules. The majority of the tubules present had an altered morphology. Many tubules were dilated, with large moderately basophilic cells and pleomorphic nuclei, resembling the AP segments noted at $4 \mathrm{wk}$. Tubules had a very wide, round to oval shape. The epithelium had a brush border and occasional long cilia extended into the lumen. Cytoplasmic blebs protruded from the surface of some epithelial cells. (Fig. $4 \mathrm{~B}, \mathrm{C}$ ). Weak GGT activity could be seen in the brush border of a few AP tubules. (Fig. 4D). These AP tubules contained BrdU-labeled nuclei (3\%) (Fig. 4E).

Some nephrons with almost normal morphology were present in a few fish. These tubules were more basophilic than those of control fish, but the basic shape and size of the tubules and their epithelia were like those of normal nephrons. These tubules were probably in maturing, newly formed nephrons. Intense GGT activity was present in these tubules (Fig. 4D).

Distal tubules and collecting ducts had normal morphology although some contained calcium deposits in their lumens (Fig. 4F)

\section{Experiment 2: BrdU pulse label on Day 4}

HCBD-treated fish, given a pulse of BrdU on Day 4 and sacrificed on Day 7 , had numerous labeled nuclei in the regenerating proximal tubules $(19 \%)$, distal tubules ( $8 \%$ ), small and large collecting ducts $(29 \%$, $27 \%$ ), and basophilic clusters (37\%) (Fig. 5). These were significantly greater $(p<0.05)$ than the respective values of the control fish which received the same BrdU regime.

Fig. 4. Carassius auratus. (A) Fibrotic glomerulus (arrow) $10 \mathrm{wk}$ following HCBD-treatment. Hematoxylin and eosin stain; bar $=$ $10 \mu \mathrm{m}$. (B). Large collecting duct adjacent to dilated 'altered' proximal segments $10 \mathrm{wk}$ following HCBD-treatment. Hematoxylin and eosin stain; bar $=50 \mu \mathrm{m}$. (C) 'Altered' proximal segment $10 \mathrm{wk}$ following HCBD-treatment. Cytoplasmic blebs and cilia extend into the lumen. Cells are slightly basophilic and much taller than those of normal proximal segments. Note also the thickened Bowman's capsule surrounding the glomerulus in the bottom left. Hematoxylin and eosin stain; bar $=20 \mu \mathrm{m}$. (D) Gamma glutamyl transpeptidase staining in a developing nephron and 'altered' proximal segments (arrows) 10 wk following HCBD-treatment. Weigert's acid iron chloride hemalum counterstain; bar $=50 \mu \mathrm{m}$. (E) Immunoperoxidase staining of BrdU incorporation in nuclei of 'altered' proximal segments $10 \mathrm{wk}$ after HCBD-treatment. Hematoxylin counterstain; bar $=20 \mu \mathrm{m}$. (F) Mineral deposit (arrow) in a small collecting duct $10 \mathrm{wk}$ after HCBD-treatment. This material was positive for calcium when stained with Von Kossa's stain. Hematoxylin and eosin stain; bar $=20 \mu \mathrm{m}$. (G) Immunoperoxidase staining of BrdU incorporation in nuclei of small collecting ducts on Day 7 in a fish given daily BrdU injections on Days 4,5,6, and 7 following HCBD-treatment. Most of the epithelial cell nuclei in the ducts are labeled. Hematoxylin counterstain; bar $=20 \mu \mathrm{m}$. (H) Immunoperoxidase staining of extensive BrdU incorporation in nuclei of a large collecting duct on Day 7 in a fish given daily BrdU injections on Days 4,5,6, and 7 following HCBD-treatment. Hematoxylin counterstain; bar $=50 \mu \mathrm{m}$ 

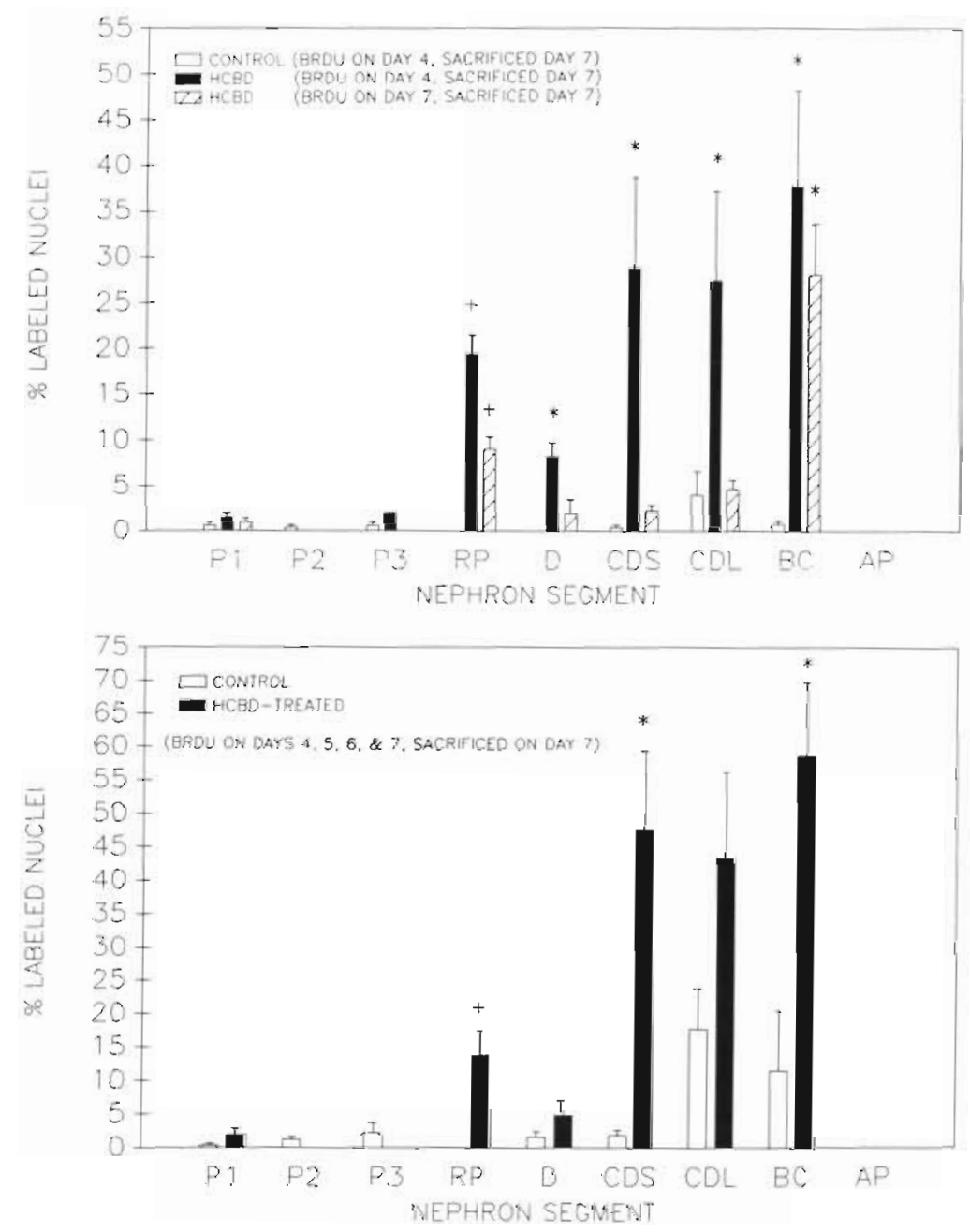

Fig 5. Carassius auratus. Percent labeled nuclei in the different nephron segments in control and $\mathrm{HCBD}$-treated fish given a pulse of BrdU on Day 4 and sacrificed on Day 7 ; and in HCBD-treated fish given BrdU on Day 7 and sacrificed on Day 7. The regenerating epithelium of fish given BrdU on Day 4 contained labeled nuclei on Day 7. Abbreviations and significance as in Fig. 1
Fig. 6. Carassius auratus. Percent labeled nuclei in control and HCBD-treated fish given daily injections of BrdU on Days 4,5,6 and 7. Abbreviations and significance as in Fig. 1
The group of HCBD-treated fish which received BrdU on Day 7 and were sacrificed on Day 7 had labeled nuclei in the regenerating proximal tubules $(9 \%)$. The percent labeled nuclei of these regenerating tubules $(9 \%)$ was significantly less when compared to those from the HCBD-treated fish given BrdU on Day 4 and sacrificed on Day $7,(p<0.05)$. Since BrdU given to the HCBD-treated fish on Day 4 was primarily incorporated into the nuclei of the large collecting ducts, cells most likely migrated up the nephron to the denuded basement membrane during Days 5 to 7. By Day 7, some of these migrating cells also synthesized DNA and divided in the regenerating tubules.

\section{Experiment 3: BrdU 'continuous' label Days 4 through 7}

$\mathrm{HCBD}$-treated fish, given daily injections of BrdU on Days 4 through 7 and sacrificed on Day 7 , had numer- ous labeled nuclei in the regenerating proximal tubules $(14 \%)$, distal tubules $(5 \%)$, small and large collecting ducts $(48 \%, 43 \%)$ and basophilic clusters $(59 \%)$ (Fig. $4 \mathrm{G}, \mathrm{H})$. The distribution of labeling was similar to that seen in HCBD-treated fish given a pulse of BrdU on Day 4 and sacrificed on Day 7 (Fig. 6). There were, however, greater numbers of labeled nuclei in the nephrons of 'continuously' labeled HCBD-treated fish than in fish given only a pulse of BrdU.

\section{DISCUSSION}

Regeneration of the epithelium following injury is a vital process in many organs of both mammals and fish (Oliver 1915, Bullock et al. 1978, Keenan et al. 1982, Chretien \& Pisam 1986). An understanding of this response is essential when examining injured tissues. Although renal tubular regeneration has been well documented in the mammal (Cuppage \& Tate 1967. 
Fig. 7. Carassius auratus. Major events during toxicity, regeneration, and development of new nephrons in goldfish Carassius auratus following HCBD exposure. Control: Nephron with normal segments. Only a few nuclei incorporated BrdU (seen as black nuclei in the epithelium). Basophilic clusters were small and inactive. Day 4: Extensive vacuolation and necrosis in P2 and P3. Many collecting duct nuclei incorporated BrdU. Week 1. Some glomeruli were dilated, P1 epithelial cells contained small vacuoles, P2 and P3 could not be identified. Regenerating proximal segments (RP) contained flattened, basophilic cell, some of which incorporated BrdU. Basophilic clusters appeared larger and incorporated BrdU. Week 2: Thickened cells lined some Bowman's capsules. P1 segments still contained vacuoles and some cells sloughed. RP epithelial cells were more cuboidal, some contained vacuoles. Basophilic clusters had developed into short nephron segments, and contained much BrdU. Calcium casts were present in distal tubules and collecting ducts. Week 3: P1 segment epithelium was vacuolated, RP segments were collapsed or vacuolated and necrotic. Developing nephrons incorporated BrdU. Calcium casts were present in distal tubules and collecting ducts. Week 4: Large, dilated 'altered' proximal (AP) segments were present. The epithelium of these segments and of the regenerating segments was vacuolated and had cytoplasmic blebs extending into the lumen. Developing nephrons continued to incorporate BrdU. Week 10: Altered proximal segments still contained vacuolated epithelial cells. Developing nephrons were larger and had developed mature characteristics. Fibrotic glomeruli were noted at this time. Abbreviations are (G) glomerulus; (N) neck; (P1, P2, P3) proximal segments $1,2,3$; $(R P)$ regenerating proximal segments; (D) distal segments; (CDS) small collecting ducts; (CDL) large collecting ducts; (BC) basophilic clusters; (AP) 'altered' proximal segments
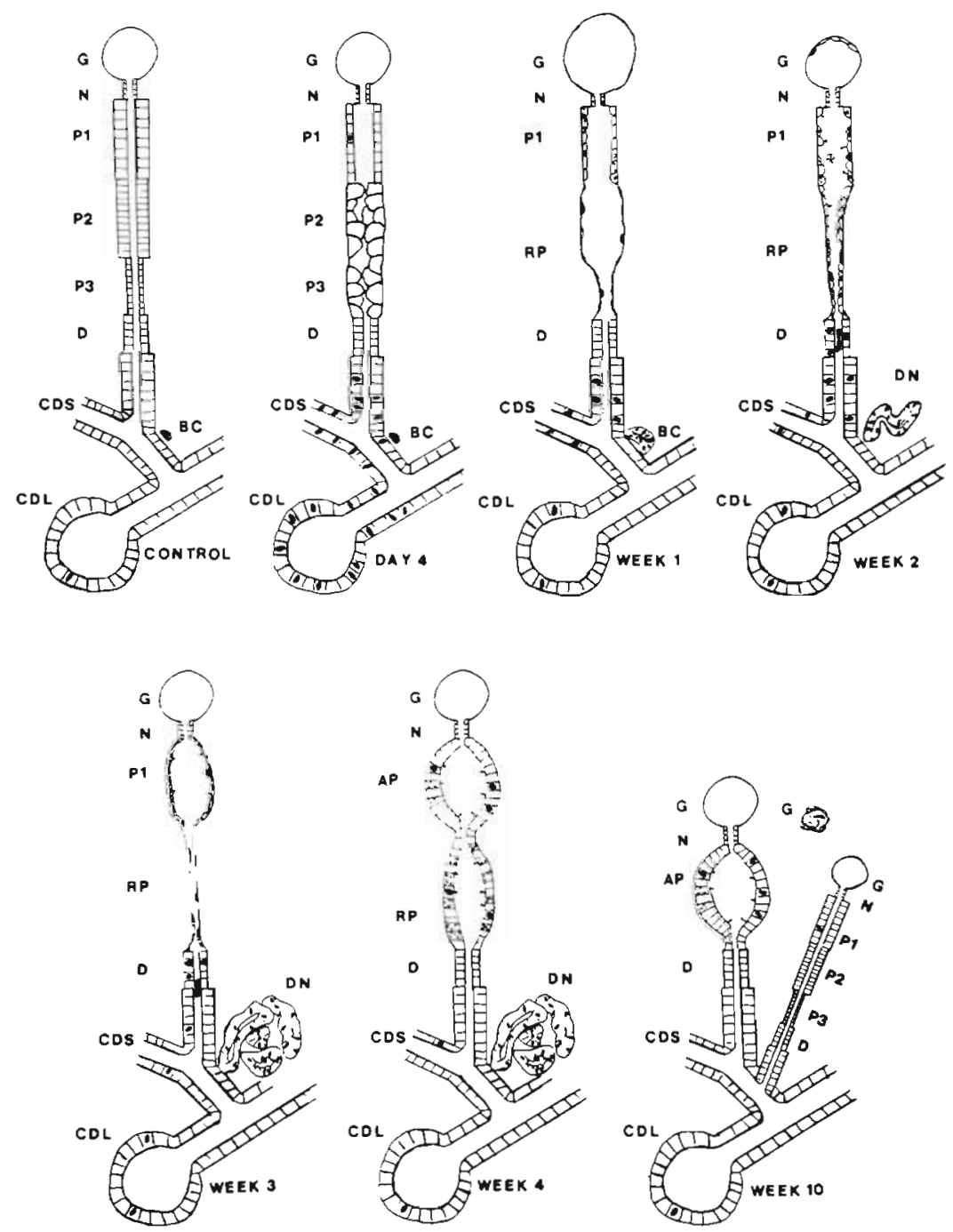

Ishmael et al. 1982), no studies have investigated this process in fish kidney.

The goals of our investigations were to determine if fish proximal tubules were capable of regeneration after a toxic injury and to characterize this response. We have shown that a sublethal dose of HCBD caused marked proximal tubular necrosis (Reimschuessel et al. 1989). The initial massive tubular necrosis was followed at $1 \mathrm{wk}$ by a repopulation of the nephron by a flattened squamous basophilic epithelium (Fig. 7). As these cells matured, they developed a paler, lavender appearance. By Week 2, some regenerating tubules had a morphology similar to the epithelium of P3-short cuboidal cells with eosinophilic cilia in their lumens. As cells in these tubules developed more differentiated characteristics they also developed cytoplasmic vacuoles, indicating possible continued HCBD-induced damage. The time point at which the regenerating epithelium developed vacuoles may have been when the cells started producing enzymes such as renal Blyase. In the mammal, renal B-lyase metabolizes the cysteine conjugate of $\mathrm{HCBD}$ producing reactive compounds which in turn cause the toxicity (Nash et al. 1984, Jones et al. 1986, Dekant et al. 1988). The metabolic fate of HCBD in fish is unknown. Preliminary data from our laboratory indicate that the renal toxicity of HCBD is dependent upon B-lyase activity (Reimschuessel et al. unpubl. obs.). It appears, however, that the regenerating epithelium is not sensitive to the HCBD-induced toxicity until it develops more mature 
characteristics. Three and 4 wk following the initial HCBD injection, fewer regenerating tubules were observed. Their epithelial cells were vacuoldted and frequently necrotic. By Week 10 there were few regenerating tubules present. The regenerating tubules present at that time contained vacuolated epithelial cells.

In the rat, the regenerating epithelial cells migrate primarily from the segments distal to the injury (Haagsma \& Pound 1980). Cells adjacent to the injured segment flatten and migrate along the basement membrane. Tritiated thymidine labeling has demonstrated that these cells synthesize DNA and divide as they migrate (Cuppage \& Tate 1967). Labeling has also been observed in the distal convoluted tubules and collecting ducts (Haagsma \& Pound 1980, Klingler et al. 1980 ) indicating that the distal part of the nephron may be involved with the regenerative process. In those studies, regenerating epithelial cells developed mature characteristics between 11 and 28 d post-injury, with those at the distal end of the regenerated segment being particularly more advanced than those in the middle portions.

Recently, studies have demonstrated the importance of the distal portions of the nephron in response to injury. Andersson \& Jennische (1988), reported Insulinlike Growth Factor I (IGF-I) immunoreactivity in cells of the thin loop of Henle and the collecting ducts. These investigators also found that IGF-I immunoreactivity was present in regenerating cells after ischemic injury. They postulated that the regenerating cells have their origin in the thin loop of Henle. Since local increases in IGF-I were important in the compensatory growth of the kidney following unilateral nephrectomy (Stiles et al. 1985, Fagin \& Melmed 1987), the cells distal to the injury may be providing a paracrine growth stimulus.

In the present studies, BrdU was used to demonstrate DNA synthesis in the different segments of the nephron. BrdU, an analogue of thymidine, is incorporated into DNA during S-phase. Proliferating cells can be identified using a monoclonal antibody to BrdU (Gratzner 1982, Morstyn et al. 1986). This immunohistochemical method is sensitive and specific, uses no radioactive chemicals, and provides results much more rapidly than tritiated thymidine (De Fazio et al. 1987. Schutte et al. 1987).

In the pulse labeling Expt 1, extensive incorporation of BrdU occurred in the collecting ducts on Day 4 following HCBD-treatment (Fig. 1). Labeling also occurred in the regenerating proximal epithelium and distal tubules during the following weeks. The control fish had little labeling in the collecting ducts and almost no labeling in the proximal and distal segments of the nephron.

The results of Expt 2 showed that some of the repopulation of the proximal tubules occurred by migration. The regenerating proximal epithelium (RP) contained more labeled cells in fish injected with BrdU on Day 4 and sacrificed on Day 7 than the RP of fish given the BrdU on Day 7 and sacrificed on Day 7 . On Day 4, the epithelium of P2 and P3 was extensively vacuolated and undergoing necrosis (Reimschuessel et al. 1989). Because no regenerating epithelium was evident on Day 4, the cells which incorporated the BrdU at that time must have migrated onto the denuded epithelium between Day 4 and Day 7. Since some labeling occurred in the regenerating tubules on Day 7 , the migrating cells must have divided. The majority of the labeled nuclei on Day 4 were in the collecting ducts. These cells may provide replacements for cells which migrated into the damaged segmenis. The 'continuous labeling' Expt 3 also demonstrated heavy BrdU labeling in the regenerating epithelium, distal tubules and collecting ducts. The distribution of labeling in the nephron segments was similar to that of the pulse labeling Expt 2, but there were many more labeled nuclei in the segments of fish receiving continuous labeling'

The development of new, immature nephrons following renal damage is a response unique to fish. Fish retain the ability to form new nephrons as they grow throughout adult life (Yasutake \& Wales 1983). Mammals, such as the rat, are able to form new nephrons for only 3 d after birth (Larsson 1975, Neiss \& Klehn 1981, Reeves \& Farquhar 1982). Neither renal regeneration following nephrotoxin administration (Oliver 1915, Cuppage \& Tate 1967. Houghton et al. 1976, Ishmael et al. 1982), nor compensatory hypertrophy following unilateral nephrectomy (Kaufman et al. 1975, Larsson et al. 1980, Kazimierczak 1982, Fine 1986) induce development of new nephrons in mammalian kidneys. Stereologic quantification showed the volume percent of the kidney occupied by the developing nephrons was greater in HCBD-treated fish 2, 3, 4 and $10 \mathrm{wk}$ post-injection than in the control fish (Reimschuessel et al. in press).

The present studies show that the goldfish Carassius auratus nephron, like that of the mammal, can regenerate the proximal tubule epithelium following toxic injury. The source of these cells appears to be primarily from the distal portions of the nephron. What signals these cells to synthesize DNA and to divide is unknown. Several theories have been proposed to explain proliferative responses in the kidney (Cuppage \& Tate 1967, Cain et al. 1976, Herbertson et al. 1987, Andersson \& Jennishe 1988). The nephrotoxic substance could have a direct effect on the cells, inducing them to divide. The toxicant may, however, indirectly stimulate the cells to divide by inducing the production or release of mitogens, or by removing an inhibitor of 
division. The presence of injured cells alone can stimulate a proliferative response by renal tubular epithelium (Cain et al. 1976). Since HCBD induces massive necrosis, a mitogenic substance released by the injured cells could be the cause of the proliferative response. It is possible that, in addition to its nephrotoxic effects, $\mathrm{HCBD}$ is a direct acting mitogen. HCBD is a renal carcinogen, but the mechanism of its carcinogenicity is unknown (Kociba et al. 1977. Stott et al. 1981a).

'Altered' proximal tubules (AP) were observed at 4 and $10 \mathrm{wk}$ post-HCBD injection. The cells in these tubules resembled the hyperplastic cells seen in proximal tubules of rats treated with lead (Choie \& Richter $1972 \mathrm{a}, \mathrm{b})$ and other carcinogens (Hard \& Butler 1971, Lipsky \& Trump 1988). It is uncertain at this time if these tubules are a preneoplastic change or are an adaptation to the continued injury caused by $\mathrm{HCBD}$. The AP tubules demonstrated faint GGT activity and continued BrdU incorporation $10 \mathrm{wk}$ post-HCBD treatment. Further studies to determine the fate of these tubules are currently underway.

Acknowledgements. The authors would like to express their gratitude to Christina Hauf, Andrew Kane and Ann Muhvich for their support and help maintaining the fish. We also thank Dr Thomas Jones for his advice and many helpful discussions.

\section{LITERATURE CITED}

Andersson, G., Jennische, E. (1988). IGF-I immunoreactivity is expressed by regenerating renal tubular cells after ischaemic injury in the rat. Acta physiol. scand. 132: 453-456

Boti, Z. S., Kobor, J., Ormos, J. (1982). Activity of glucose-6phosphatase in regenerating tubular epithelium in rat kidney after necrosis induced with mercuric chloride: a light and electron microscopical study. J. exp. Pathol. 63: 615-624

Bullock, A. M., Marks, R., Roberts, R. J. (1978). The cell kinetics of teleost fish epidermis: Epidermal mitotic activity in relation to wound healing at varying temperatures in plaice (Pleuronectes platessa). J. Zool., Lond. 185: 197-204

Cain, H., Egner, E., Redenbacker, M. (1976). Increase of mitosis in the tubular epithelium following intrarenal doses of various kidney homogenates and homogenate fractions in the rat. Virchows Arch. (B. Zellpath.) 22: 55-72

Choie D. D., Richter, G. W. (1972a). Cell proliferation in rat kidney induced by lead acetate and effects of uninephrectomy on the proliferation. Am. J. Pathol. 66: 265-275

Choie D. D., Richter, G. W. (1972b). Cell proliferation in rat kidneys after prolonged treatment with lead. Am. J. Path. 68: 359-369

Chretien M., Pisam, M. (1986). Cell renewal and differentiation in the gill epithelium of fresh or salt-water adapted euryhaline fish as revealed by $\left({ }^{3} \mathrm{H}\right)$-thymidine radioautography. Biol. Cell 56: 137-150

Cuppage, F. E., Tate, A. (1967). Repair of the nephron following injury with mercuric chloride. Am. J. Path. 51: 405-429

De Fazio, A., Leary, J. A., Hedley, D. W., Tattersall, M. H. N. (1987). Immunohistochemical detection of proliferating cells in vivo. J. Histochem. Cytochem. 35: 571-577
Dekant, W., Berthold, K., Vamvakas, S., Henschler, D. (1988). Thioacylating agents as ultimate intermediates in the B-lyase catalyzed metabolism of S-(pentachlorobutadienyl)-L-cysteine. Chem-biol. Interactions 67: $139-148$

Droy, B. F., Miller, M. R., Freeland, T. M., Hinton, D. (1988). Immunohistochemical detection of $\mathrm{CCl} 4$-induced mitosisrelated DNA synthesis in livers of trout and rat. Aquat Toxic. 13: 155-166

Edwards, J. G., Schnitter, C. (1933). The renal unit in the kidney of vertebrates. Am. J. Anat. 53: 55-87

Endo, M., Kimura, M. (1982). Histolocial and enzyme histochemical studies on the nephrons of the freshwater fishes Cyprinus carpio and Carassius auratus. J. Morphol. 173: 29-33

Fagin, J. A, Melmed, S. (1987). Relative increase in insulinlike growth factor I messenger ribonucleic acid levels in compensatory renal hypertrophy. Endocrinology 120: $718-724$

Fine, L. (1986). The biology of renal hypertrophy. Kidney int. 29: $619-634$

Gage, J. C. (1970). The subacute inhalation toxicity of 109 industrial chemicals. Br. J. ind. Med. 27: 1-18

Gratzner H. G. (1982). Monoclonal antibody to 5-bromo- and 5-iododeoxyuridine: a new reagent for detection of DNA replication. Science 218: 474-475

Haagsma, B. H., Pound, A.W. (1980). Mercuric chlorideinduced tubulonecrosis in the rat kidney: the recovery phase. Br. J. exp. Pathol. 61: 229-241

Hard, G. C., Butler, W. H. (1971). Ultrastructural aspects of renal adenocarcinoma induced in the rat by dimethylnitrosamine. Cancer Res. 31: 366-372

Hentschel, H., Elger, M. (1988). The distal nephron in the kidney of fishes. Adv. Anat. Embryol. Cell Biol. 108: 1-151

Herbertson B. M., King, A. J., Allen, J. (1987). Epithelial cell proliferation in the rat urinary system induced by parenteral injection of lead salts. Br. J. exp. Pathol. 68: $167-177$

Hickman, C. P. Jr, Trump, B. F. (1969). The kidney. In: Hoar, W. S., Randall, D. J. (eds.), Fish physiology, Vol 1. Academic Press, New York. p. 91-239

Hinton D. E., Lantz, R. C., Hampton, J. A., McCuskey, P. R., McCuskey, R. S. (1987). Normal versus abnormal structure: considerations in morphologic responses of teleosts to pollutants. Environ. Hlth Perspectives 71: 139-146.

Houghton D. C., Hartnett, M. Campbell-Boswell, M., Porter G., Bennett, W (1976). A light and electron microscopic analysis of gentamicin nephrotoxicity in rats. Am. J. Path. 82: $589-611$

IARC (1979). Hexachlorobutadiene. In: IARC Monographs on the evaluation of the carcinogenic risk of chemicals to humans. 20: 179-193

Ishmael, J., Pratt, I., Lock, A. (1982). Necrosis of the pars recta (S3 segment) of the rat kidney produced by hexachloro1:3-butadiene. J. Pathol. 138: 99-113

Johnson, R. D., Bergman, H. L. (1984). Use of histopathology in aquatic toxicology: a critique. In: Cairns, V. W., Hodson, P. V., Nriagu, J. O. (ed) Contaminant Effects on fisheries. Wiley-Interscience, New York, p. 19-36

Jones, T. W., Wallin, A., Thor, H., Gerdes, R. G., Ormstad, K., Orrenius, S. (1986). The mechanism of pentachlorobutadienyl-glutathione nephrotoxicity studied with isolated rat renal epithelial cells. Archs Biochem. Biophys. 251: $504-513$

Kaufman, J. M., Hardy, R., Hayslett, J. P. (1975). Age-dependent characteristics of compensatory renal growth. Kidney int. 8: $21-26$ 
Kazimierczak, J. (1982). Morphology and enzyme histochemistry of the kidney during normal and compensatory growth in immature rats. In: Spitzer, A. (ed) The kidney during development: morphology and function. Masson Publishing, New York, p. 31-38

Keenan, K. P., Combs, J. W., McDowell, E. M. (1982). Regeneration of hamster tracheal epithelium after mechanical injury: I. Focal lesions: quantitative morphologic study of cell proliferation. Virchows Arch (B: Zellpath.) 41: 193-214

Klingler, E. L. Jr., Evan, A. P., Anderson, R. E. (1980). Folic acid-induced renal injury and repair. Arch. Pathol. Lab. Med 104:87-93

Kociba, R. J., Keyes, D. G., Jersey, G. C., Ballard, J. J. Dittenber, D. A., Quast, J. F., Wade, C. E., Humiston, C. G., Schwetz, B. A. (1977). Results of a two year chronic toxicity study with hexachlorobutadiene in rats. Am. ind. Hygiene. Assoc. J. 38, 589-602

Larsson, L., (1975) The ultrastructure of the developing proximal tubule in the rat kidney. J. Ultrastruc. Res. 51: 119-139

Larsson, L., Aperia, A., Wilton, P. (1980). Effect of normal development on compensatory renal growth. Kidney int. 18: $29-237$

Laska A. L., Bartell, C. K., Laseter, J. L. (1976). Distribution of hexachlorobenzene and hexachlorobutadiene in water soil, and selected aquatic organisms along the lower Mississippi River, Louisiana. Bull. Environ. Contam. Toxicol. 15: $535-542$

Lipsky, M. M., Trump, B. F. (1988). Chemically induced renal epithelial neoplasia in experimental animals. In: Richter G. W. Solez, K. (eds.) International review of experimental pathology Vol 30. Academic Press, Inc. New York, p. $357-381$

Lock, E. A., Ishmael, J. (1979). The acute toxic effects of hexachloro-1:3-butadiene on the rat kidney. Arch. Toxi. 43: $47-57$

Longley, J. B., Fisher, E. R. (1954). Alkaline phosphatase and the periodic acid schiff reaction in the proximal tubule of the vertebrate kidney. Anatomical Record 120: 1-21

Luna, L. G., (1968). Manual of histologic staining methods of the Armed Forces Institute of Pathology, 3rd edn. McGraw-Hill Book Co., New York

McDowell, E. M., Trump, B. F. (1976). Histologic fixatives suitable for diagnostic light and electron microscopy. Arch. Path. Lab. Med. 100: 405-414

Morstyn, G., Pike, K., Gardner, J., Ashcroft, R., De Fazio, A. Bhathal, P. (1986). Immunohistochemical identification of proliferating cells in organ culture using bromodeoxyuridine and a monoclonal antibody. J. Histochem. Cytochem. 34: 697-701

Nash, J. A., King, L. J., Lock, E. A., Green, T. (1984). The metabolism and disposition of hexachloro-1:3-butadiene in the rat and its relevance to nephrotoxicity. Toxic, applied Pharmac. 73: 124-137

Neiss, W. F., Klehn, K. L. (1981). The postnatal development of the rat kidney, with special reference to the chemodifferentiation of the proximal tubule. Histochemie 73 251-268

Ogawa, M. (1962). Comparative study on the internal structure of the teleostean kidney. Sci. Rep. Saitama Univ. Ser B 4: 107-129

Responsible Subject Editor: Dr G. Peters, Hamburg. F.R. Germany
Oliver, J. (1915). The histogenesis of chronic uranium nephritis with especial reference to epithelial regeneration. J exp. Med 21: 425-541

Pearson, C. R., McConnel, G. (1975). Chlorinated C1 and C2 hydrocarbons in the marine environment. Proc. R. Soc. (Ser. B) 189: 305-332

Reeves, W. H., Farquhar, M. G. (1982). Maturation and assembly of the glomerular filtration surface in the newborn rat kidney. Studies using electron-dense tracers, cationic probes, and cytochemistry. In: Spitzer, A. (ed.) The kidney during development: morphology and function, Masson Publishing, New York, p. 97-113

Reimschuessel, R., Bennett, R. O., May, E. B., Lipsky, M. M. (1989). Renal histopathological changes in the goldfish (Carassius auratus) after sublethal exposure to hexachlorobutadiene. Aquat Toxic. 15: 169-180

Reimschuessel, R., Bennett, R. O., May, E. B., Lipsky, M. M. (in press). Development of newly formed nephrons in the goldfish kidney foilowing hexacilutubutatione-indicod nephrotoxicity. Toxic. Path.

Schutte, B., Reynders, M. M. J., Bosman, F. T., Blijham, G. H. (1987). Studies with anti-bromodeoxyuridine antibodies. II. Simultaneous immunocytochemical detection of antigen expression and DNA synthesis by in vivo labeling of mouse intestinal mucosa. J Histochem. Cytochem. 35: $371-374$

Sindermann, C. J., Bang, F. B., Christensen, N. O., Dethlefsen, V., Harshbarger, J. C., Mitchell, J. R., Mulcahy, M. F. (1980). The role and value of pathobiology in pollution effects monitoring programs. Rapp. P.v. Reun. Conspen int. Explor Mer. 179: 135-151

Stiles, A. D., Sosenko, I. R. S., Dercole, A. J., Smith, B. T. (1985). Relation of kidney tissue somatomedin-C/insulinlike growth factor I to postnephrectomy renal growth in the rat. Endocrinology 177: 2397-2401

Stott W. T., Quast, J. F., Watanabe, P. G. (1981a). Differentiation of the mechanisms of oncogenicity of 1,4-Dioxane and 1,3-hexachlorobutadiene in the rat. Toxicol. appl. Pharmacol. 60: $287-300$

Stott, W T., Reitz, R. J., Schumann, A. M. Watanabe, P. G. (1981b). Genetic and nongenetic events in neoplasia. Food Cosmet. Toxicol. 19: 567-576

USEPA (1980). Ambient water quality criteria for hexachlorobutadiene. EPA 440/5-80-053

Vacca, L. L. (1985). Laboratory manual of histochemistry. Raven Press, New York, p. 139

Wellwood, J. M., Lovell, D., Thompson, A. E., Tighe, J. R. (1976). Renal damage caused by gentamicin: A study of the effects on renal morphology and urinary enzyme excretion. J. Path. 181, 171-182

Yasutake, W T., Wales, J. H. (1983). Microscopic anatomy of salmonids: an atlas. U.S. Department of the Interior, Resource Publication 150 Washington, D.C. p. 97

Yip, G., (1976). Survey for hexachloro-1,3-butadiene in fish, eggs, milk, and vegetables. J. Ass. off. analyt. Chem. 59: $559-561$

Yurawecz, M. P., Dreifuss, P A., Kamps, L. R. (1976). Determination of hexachloro-1,3-butadiene in spinach, eggs, fish, and milk by electron capture gas-liquid chromatography J. ass. off. analyt. Chem. 59: 552-558

Manuscript first received: December 12, 1989

Revised version accepted: April 10, 1990 